\title{
MICROSPHERE SIZE INFLUENCES THE FOREIGN BODY REACTION
}

\author{
J. Zandstra ${ }^{1, *}$, C. Hiemstra ${ }^{2}$, A.H. Petersen ${ }^{1}$, J. Zuidema², M.M. van Beuge ${ }^{1}$, S. Rodriguez ${ }^{3}$, A.A.R. Lathuile ${ }^{3}$, \\ G.J. Veldhuis ${ }^{3}$, R. Steendam², R.A. Bank ${ }^{1}$ and E.R. Popa ${ }^{1}$
}

${ }^{1}$ Department of Pathology and Medical Biology, University of Groningen, University Medical Centre Groningen, Groningen, The Netherlands

${ }^{2}$ InnoCore Pharmaceuticals, Groningen, The Netherlands

${ }^{3}$ Nanomi BV, Oldenzaal, The Netherlands

\begin{abstract}
Biodegradable poly-(DL-lactide-co-glycolide) (PLGA) microspheres (MSP) are attractive candidate vehicles for site-specific or systemic sustained release of therapeutic compounds. This release may be altered by the host's foreign body reaction (FBR), which is dependent on the characteristics of the implant, e.g. chemistry, shape or size. In this study, we focused on the characterisation of the influence of MSP size on the FBR. To this end we injected monodisperse MSP of defined size (small $5.8 \mu \mathrm{m}$, coefficient of variance (CV) $14 \%$ and large $29.8 \mu \mathrm{m}, \mathrm{CV}$ $4 \%$ ) and polydisperse MSP (average diameter $34.1 \mu \mathrm{m}, \mathrm{CV}$ $51 \%$ ) under the skin of rats. MSP implants were retrieved at day 7, 14 and 28 after transplantation. The FBR was studied in terms of macrophage infiltration, implant encapsulation, vascularisation and extracellular matrix deposition. Although PLGA MSP of all different sizes demonstrated excellent in vitro and in vivo biocompatibility, significant differences were found in the characteristics of the FBR. Small MSP were phagocytosed, while large MSP were not. Large MSP occasionally elicited giant cell formation, which was not observed after implantation of small MSP. Cellular and macrophage influx and collagen deposition were increased in small MSP implants compared to large MSP. We conclude that the MSP size influences the FBR and thus might influence clinical outcome when using MSP as a drug delivery device. We propose that a rational choice of MSP size can aid in optimising the therapeutic efficacy of microsphere-based therapies in vivo.
\end{abstract}

Keywords: Biocompatibility (in vivo), cytocompatibility (in vitro), collagens, tissue-material interactions, foreign body response.

\footnotetext{
*Address for correspondence:

Jurjen Zandstra, M.Sc

University Medical Hospital Groningen

Dept. of Pathology \& Medical Biology

Hanzeplein 1

9713 GZ Groningen, The Netherlands

Telephone Number: +31-50-3615881

FAX Number: +31-50-3611911

E-mail: j.zandstra@umcg.nl
}

\section{Introduction}

Poly-(DL-lactide-co-glycolide) (PLGA)-based microspheres (MSP) are attractive candidate vehicles for controlled delivery of therapeutic compounds. Several therapies based on PLGA MSP as a drug delivery system have been developed to treat for instance cancer (Enriquez et al., 2013; Okada, 1997), growth hormone deficiency (Jones et al., 1997), or to regenerate bone (Lanao et al., 2013; Felix Lanao et al., 2013; Hoekstra et al., 2013). Site-specific or systemic sustained release of therapeutic compounds by means of injectable drug delivery vehicles will, conceivably, receive increasing attention in the future, since it allows for optimal therapeutic effect at the site of interest, while minimising systemic loss and undesired side effects of the drug in the rest of the body. Synthetic, biodegradable polymers are attractive candidates for generating tuneable drug delivery vehicles, since both their chemical and their physical properties can be customised for the delivery of specific drugs and for applications at specific sites in the body (Lu et al., 2009). However, polymer drug vehicles will inevitably elicit an inflammatory, or so-called foreign body reaction (FBR) in vivo, since they are recognised by the immune system as foreign to the body (Anderson, 2001; Onuki et al., 2008). This FBR typically consists of infiltration of inflammatory cells into the foreign body implant and encapsulation thereof, in an attempt to protect and isolate surrounding tissue from and to remove the intruding object. Moreover, vascularisation of the implant and deposition of extracellular matrix around and in the foreign implant are also characteristics of the FBR.

The relationship between the physical and chemical properties of drug delivery vehicles or implant materials, including synthetic biodegradable polymers, and the extent and duration of the FBR are incompletely understood. Physical properties such as the size of the vehicle or implant, its surface topography and shape, may determine the extent of the FBR (Champion and Mitragotri, 2006). Several studies investigated the effect of MSP size on phagocytosis in vitro (Champion et al., 2008; Paul et al., 2013), on bone healing (Petrie Aronin et al., 2009), or on in vivo inflammatory responses (Gelb et al., 1994; Kusaka et al., 2014). The same holds true for chemical properties of the material and also for the type of its degradation products. Microspheric particles are interesting vehicles for in vivo drug delivery due to their capacity to release drugs controllably with respect to duration and dosage. The obvious question arises in how far the diameter of MSP affects the magnitude of the FBR and, more specifically, 
the behaviour of inflammatory cells that come in contact with these particles. Due to technical limitations, previous approaches to this question have been mainly performed using polydisperse microspheres with a broad particle size distribution (Bhardwaj et al., 2010) or roughly sizesieved MSP (Cadee et al., 2001). Interestingly, the latter study suggested that MSP diameter might, indeed, affect the nature of the FBR showing that small MSP $(<10 \mu \mathrm{m})$ induce increased lymphocyte infiltration, decreased giant cell formation and increased vascularisation compared to larger MSP $(>20 \mu \mathrm{m})$. Current progress in microsphere manufacturing technology allows the preparation of monodisperse microspheres with a narrow and wellcontrolled particle size distribution and allows us to address the relationship between MSP size and inflammatory FBR in more detail. In this study, we investigated the effect of MSP size on the magnitude and kinetics of the FBR in rats. To this end, we injected monodisperse MSP with a diameter of $5 \mu \mathrm{m}$ or $30 \mu \mathrm{m}$, and polydisperse MSP under the skin of rats and evaluated the FBR at various time points, up to one month after implantation. We chose PLGA as a model polymer for MSP generation, since it has been widely characterised in vivo, and is used in various microspherebased drug delivery products that have been approved by the FDA for use in patients (Makadia and Siegel, 2011).

\section{Materials and Methods}

\section{Chemicals}

Poly(DL-lactide-co-glycolide) (PLGA) with a 50:50 DL-lactide:glycolide monomer ratio and an intrinsic viscosity of $0.4 \mathrm{dL} / \mathrm{g}$ (Purasorb PDLG5004) was purchased from Purac Biomaterials (Gorinchem, The Netherlands). Dichloromethane (DCM) was purchased from Acros Organics (Geel, Belgium). Polyvinylalcohol (PVA) was purchased from Sigma Aldrich (Zwijndrecht, The Netherlands), Tween-20 from Fisher Scientific (Landsmeer, The Netherlands) and ultrapure water from B. Braun Medical B.V. (Oss, The Netherlands). Carboxymethyl cellulose (CMC) was purchased from Hercules (Jiangmen, China).

\section{Microsphere preparation}

Polydisperse microspheres with an average particle size of $30 \mu \mathrm{m}$ were prepared using a standard oil-in-water $(\mathrm{O} / \mathrm{W})$ single emulsion solvent extraction process using a $20 \% \mathrm{w} / \mathrm{w}$ PLGA solution in dichloromethane. The polymer solution was filtered through a $0.2 \mu \mathrm{m}$ sterilising polytetrafluoroethylene (PTFE) filter; subsequently, the polymer solution was introduced into a vigorously stirred aqueous solution containing $0.4 \mathrm{wt} . \% \mathrm{PVA}$ as emulsifier.

Monodisperse MSP were prepared by an $\mathrm{O} / \mathrm{W}$ single emulsion membrane emulsification technique using an Iris-20 and an Anemoon 3.3 microfabricated Microsieve membrane with uniform pores (Nanomi BV, Oldenzaal, The Netherlands) for the $30 \mu \mathrm{m}$ diameter MSP and the $5 \mu \mathrm{m}$ diameter MSP (Veldhuis et al., 2009), respectively, using a filtered $(0.2 \mu \mathrm{m}$ sterilising PTFE filter $) 10 \% \mathrm{w} / \mathrm{W}$ PLGA solution in dichloromethane. Membrane-emulsified
MSP were collected into a 4 wt.\% PVA containing aqueous solution.

The collected dispersions of monodisperse and polydisperse MSP were left to stir at $20-50{ }^{\circ} \mathrm{C}$ for at least $3 \mathrm{~h}$ to extract and evaporate the organic solvent. Hardened MSP were either concentrated by centrifugation (polydisperse MSP) using a Z323K centrifuge (Hermle Labortechnik, Wehingen, Germany) at $3154 \times g$ for 2 min or by filtration (monodisperse MSP) and subsequently washed repeatedly with ultrapure water containing $0.05 \mathrm{wt} \%$ Tween-20. Finally, the concentrated MSP dispersions were lyophilised. MSP were stored at $-20{ }^{\circ} \mathrm{C}$ until evaluation.

\section{Microsphere characterisation}

MSP were characterised in terms of particle size distribution by Coulter Multisizer (Beckman Coulter, Woerden, The Netherlands). The average diameter of the smaller monodisperse MSP was $5.8 \mu \mathrm{m}$ with a coefficient of variance $(\mathrm{CV})$ of the peak of $14 \%$, whereas the larger monodisperse MSP had an average particle size of $29.8 \mu \mathrm{m}$ with a of CV of $4 \%$. For sake of clarity the small monodisperse MSP in this paper are referred to as $5 \mu \mathrm{m}$ MSP and the large monodisperse MSP as $30 \mu \mathrm{m}$ MSP. Polydisperse MSP had an average diameter of $34.1 \mu \mathrm{m}$ with a CV of the peak of $51 \%$. Surface morphology of the particles was assessed by scanning electron microscopy (JCM-5000 Neoscope, Jeol, Eching, Germany). Samples were sputtered with a thin layer of gold using the JFC Neocoater (Jeol). Residual dichloromethane content of lyophilised MSP, as measured by gas chromatography using a TraceGC gas chromatograph (InterScience, Louvain La Neuve, Belgium) equipped with a CombiPal headspace module (CTC Analytics AG, Zwingen, Switzerland) and dichloromethane standards in dimethylsulphoxide in the range of 0-2000 ppm, was found to be $<600 \mathrm{ppm}$.

\section{Extraction of leachables from PLGA MSP}

To extract leachables, including residual dichloromethane, low molecular weight oligomers and residual catalyst from PLGA MSP, PLGA MSP $(0.17 \mathrm{mg} / \mathrm{mL})$ were shaken for $24 \mathrm{~h}$ at $37^{\circ} \mathrm{C}$ in complete culture medium in a pyrogenfree tube. The control polymers, polyurethane (PU) and rubber latex were treated similarly. Subsequently, solid material and supernatant were separated by centrifugation at $300 \times g$. The supernatant was immediately used for in vitro biocompatibility assays.

\section{In vitro biocompatibility assays}

The human skin fibroblast cell line PK-84 was cultured in RPMI 1640 medium (Lonza, Breda, The Netherlands) supplemented with $10 \% \mathrm{v} / \mathrm{v}$ foetal calf serum (Perbio Science, Etten-Leur, The Netherlands), 2 mM L-glutamine (Lonza), $1 \% \mathrm{v} / \mathrm{v}$ penicillin and $1 \% \mathrm{v} / \mathrm{v}$ streptomycin $(10,000 \mathrm{U} / \mathrm{mL}$, Gibco, Paisley, UK). Cell cultures were incubated at $37{ }^{\circ} \mathrm{C}$ and $5 \% \mathrm{CO}_{2}$. To test the biocompatibility of PLGA in direct contact with cells, PK84 cells $\left(15,000\right.$ cells $\left./ \mathrm{cm}^{2}\right)$ were co-seeded with $5 \mu \mathrm{m}$ MSP, $30 \mu \mathrm{m}$ MSP or polydisperse MSP $(0.1 \mathrm{mg} / 600 \mu \mathrm{L}$ complete medium). Similarly, PK-84 cells were co-incubated with negative control Poly Urethane Film made from 
2365-55D-pellethane resin (Dow Chemical, Midland, MI, USA) by Medtronic Promeon (Minneapolis, MN, USA) as a control for excellent biocompatibility, or positive control rubber latex (Hilversum Rubber Factory, Hilversum, The Netherlands) as a control for poor biocompatibility leading to rapid cell death. Both positive and negative controls were previously used in toxicology studies (De Groot et al., 2001). For direct contact assay studies, the positive and negative control materials were cut into very fine pieces. Cultures were maintained for $72 \mathrm{~h}$. Cell morphology was examined microscopically every day. After $72 \mathrm{~h}$, mitochondrial activity and cell proliferation were assessed, as described below. To test the biocompatibility of polymer degradation products (see above), PK-84 cells were seeded in 24-well plates at a cell density of 15,000 cells $/ \mathrm{cm}^{2}$. After $24 \mathrm{~h}$, medium was replaced with medium containing MSP degradation products or degradation products of polyurethane or latex, and cells were cultured for another $48 \mathrm{~h}$. Cell morphology was examined every day. After $48 \mathrm{~h}$, mitochondrial activity and cell proliferation were assessed, as described below.

\section{Mitochondrial activity assay}

Cell viability was determined by assessing mitochondrial activity, using the CellTiter $96^{\circledR}$ AQueous One Solution Cell Proliferation Assay (MTS assay, Promega Benelux BV, Leiden, The Netherlands), according to manufacturer's instructions. Briefly, cells were washed and MTS solution was added to each well and incubated for $2 \mathrm{~h}$ at $37{ }^{\circ} \mathrm{C}$. Absorbance was read at $490 \mathrm{~nm}$ using a fluorescence microplate reader (Varioscan, Thermo Fisher Scientific Inc., Breda, The Netherlands).

\section{Cell proliferation assay}

Cell proliferation was determined by cellular DNA content, using the CyQUANT assay (Invitrogen, Breda, The Netherlands), according to the manufacturer's instructions. Briefly, culture medium (including floating and dead cells) was removed, and the remaining viable cells were stored at $-80{ }^{\circ} \mathrm{C}$ for $48 \mathrm{~h}$ to allow for cell lysis. Subsequently, culture plates were thawed at room temperature and lysis buffer, demineralised water and CyQUANT GR dye stock solution were added to each well. Plates were incubated for $5 \mathrm{~min}$. in the dark and fluorescence was measured with a fluorescence microplate reader, with filters appropriate for $480 \mathrm{~nm}$ excitation and $520 \mathrm{~nm}$ emission.

\section{Assessment of bioburden in PLGA MSP}

Potential bacterial contamination in the MSP preparations was assessed by inoculation of MSP on blood agar plates and incubation at $37{ }^{\circ} \mathrm{C}$ for $4 \mathrm{~d}$. The presence of bacterial colonies was checked daily. Moreover, $1 \mathrm{mg}$ of MSP was suspended in complete culture medium, as used for in vitro cytotoxicity assays (see above), without addition of penicillin and streptomycin, and incubated at $37{ }^{\circ} \mathrm{C}$, $5 \% \mathrm{CO}_{2}$ for $7 \mathrm{~d}$. Medium was checked daily for bacterial growth. Endotoxin levels were determined using the Limulus amoebocyte lysate (LAL) assay performed by Toxikon (Toxikon Europe NV, Leuven, Belgium) and were well under the accepted FDA limits $(0.5 \mathrm{EU} / \mathrm{mL})$ for medical devices.

\section{Animals and implantation procedures}

Microspheres were injected subcutaneously in 9-11 weeks old male F344 rats (Harlan Laboratories Inc., Hillcrest, UK) weighing $240 \pm 50$ g. Rats were fed laboratory chow and acidified water ad libitum, and were housed according to institutional rules in groups of three, with 12:12 h dark/light cycles. The Animal Ethical Committee of the University of Groningen approved the experimental protocol.

MSP were resuspended in an aqueous reconstitution medium containing $0.4 \mathrm{w} / \mathrm{v} \% \mathrm{CMC}$ at a ratio of $20 \mathrm{mg}$ $\mathrm{MSP} / 150 \mu \mathrm{L} \mathrm{CMC}$. Resuspended microspheres were injected subcutaneously on the back of rats $(n=3$ rats/ polymer formulation; $n=3$ implants/rat) using a $20 \mathrm{G}$ needle for the monodisperse MSP and an 18G needle for the polydisperse MSP (Terumo Europe N.V. Leuven, Belgium) under general isoflurane $/ \mathrm{O}_{2}$ inhalation anaesthesia. MSP implants and surrounding tissue were explanted after 7 , 14 and $28 \mathrm{~d}$. Implants were fixed in Zinc fixative $(0.1 \mathrm{M}$ Tris-buffer, $3.2 \mathrm{mM}$ calcium acetate, $23 \mathrm{mM}$ zinc acetate, $37 \mathrm{mM}$ zinc chloride, $\mathrm{pH}$ 6.5-7.0; Merck, Amsterdam, The Netherlands) overnight, prior to paraffin embedding. Implants were cut into $4.0 \mu \mathrm{m}$-thick sections.

\section{(Immuno)histochemistry}

General histologic assessment of the FBR towards PLGA MSP was based on Toluidine blue staining (Fluka Chemie, Buchs, Switzerland), according to a standard staining protocol. Tissue sections were mounted in Permount (Fisher Scientific International, Waltham, MA, USA) and inspected microscopically.

Macrophages were identified by immunohistochemical detection of ED-1. Briefly, sections were deparaffinised and antigen retrieval was performed overnight in a $0.1 \mathrm{M}$ Tris- $\mathrm{HCl}$ buffer at $80{ }^{\circ} \mathrm{C}$. Sections were incubated in mouse-anti-rat ED-1 monoclonal antibody for $1 \mathrm{~h}(10 \mu \mathrm{g} /$ mL; MCA341R, AbD Serotec, Dusseldorf, Germany) and, subsequently, in horseradish peroxidase-conjugated rabbit-anti-mouse polyclonal antibody for $30 \mathrm{~min}(13 \mu \mathrm{g} /$ $\mathrm{mL}$; DAKO, Glosstrup, Denmark). Enzyme activity was developed using 3-amino-9-ethylcarbazole (AEC; SigmaAldrich, Zwijndrecht, The Netherlands) as a substrate. Washing and blocking of non-specific binding sites and endogenous peroxidase was performed according to standard procedures. Sections were mounted in Kaisers glycerine.

Myofibroblasts were detected by immunohistochemical staining for alpha smooth muscle actin ( $\alpha$ SMA). Briefly, slides were deparaffinised and antigens were retrieved overnight in a $0.1 \mathrm{M}$ Tris- $\mathrm{HCl}$ buffer at $80{ }^{\circ} \mathrm{C}$. Tissue sections were incubated in mouse $\alpha \mathrm{SMA}$ monoclonal antibody (Clone 1A4; $0.44 \mu \mathrm{g} / \mathrm{mL}$; DAKO) for $1 \mathrm{~h}$. Subsequently, tissue sections were washed and endogenous peroxidase was blocked with a $0.1 \% \mathrm{H}_{2} \mathrm{O}_{2}$ /phosphatebuffered saline (PBS) solution for $10 \mathrm{~min}$. Finally, sections were incubated in horseradish-conjugated rabbit-antimouse polyclonal antibody ( $13 \mu \mathrm{g} / \mathrm{mL}$; DAKO) for $30 \mathrm{~min}$, rinsed in PBS, incubated with AEC and finally mounted in Kaisers glycerine.

Connective tissue was visualised by Masson trichrome staining. Briefly, sections were deparaffinised and fixed in 
Bouin's fixative for $4 \mathrm{~min}$ at $51{ }^{\circ} \mathrm{C}$. Slides were stained with Weighert's iron haematoxylin for $10 \mathrm{~min}$, rinsed with $37^{\circ} \mathrm{C}$ tap water (10 min) and stained with Biebrich scarlet-acid fuchsin solution (15 min). Sections were differentiated in phosphomolybdic-phosphotungstic acid solution (15 min), washed, and stained with Aniline blue solution (10 min). Finally, sections were differentiated in $1 \%$ acetic acid solution ( $10 \mathrm{~s})$, washed, dehydrated quickly by dipping in alcohol followed by xylene, and mounted in Permount (Thermo Fisher Scientific Inc.). Sections were washed in demineralised water between incubation steps, unless otherwise indicated. To confirm extracellular matrix (ECM) deposition, with a focus on collagens, we performed a Picrosirius red staining. Briefly, sections were deparaffinised, rehydrated and stained with Picrosirius red solution for $1 \mathrm{~h}$. After washing twice with acidified water $(0.5 \% \mathrm{v} / \mathrm{v}$ acetic acid glacial in demineralised water $)$, sections were dehydrated quickly (see above) and mounted in Permount.

\section{Quantifications}

Stainings were evaluated using a Leica DM 2000 microscope. For morphometric quantifications, five representative photomicrographs $(40 \times 10$ objective magnification) within implants were taken per tissue section, using a Multispectral Imaging Camera (Perkin Elmer, Groningen, The Netherlands). Photomicrographs were analysed using Nuance 3.0 software (Perkin Elmer), which allows exquisite detection of specific signal (stained area) without interference from background noise. Stained areas were quantified for each specific staining and expressed as average surface area in square micrometer per high power field (HPF, $400 \mathrm{x}$ magnification with high resolution). Cellularity was quantified by digital counting of nuclei in photomicrographs of Toluidine-blue stained sections. MSP diameters were determined by measuring 50 MSP per implant using an Olympus BX50 camera (Olympus, Tokyo, Japan) with Cell^ ${ }^{\wedge}$ software (Olympus Soft Imaging Solution GmbH, Münster, Germany).

\section{Statistics}

Statistical differences between groups were determined using a two-way ANOVA, followed by Bonferroni post hoc analysis, using GraphPad Prism version 6 (GraphPad Software, La Jolla, USA). $p$ values $<0.05$ were considered to be statistically significant. Data are shown as mean \pm standard error of the mean (SEM).

\section{Results}

\section{In vitro biocompatibility of PLGA MSP}

All PLGA MSP, before investigating their biocompatibility in vitro or in vivo were checked for endotoxin contamination by Toxicon (Leuven, Belgium) and for the presence of bacteria. We continued our experiments when there was an absence of bacterial growth in our MSP inoculated agar plates and medium containing MSP for at least $72 \mathrm{~h}$. Secondly, endotoxin results obtained from Toxicon using the Limulus amoebocyte lysate assay for $20 \mathrm{mg}$ MSP in
$40 \mathrm{~mL}$ extraction fluid was less than $0.5 \mathrm{EU} / \mathrm{mL}$ or less than $20 \mathrm{EU} /$ device.

The biocompatibility of PLGA MSP has been previously described (Shive and Anderson, 1997). Nevertheless, we reassessed this biocompatibility, reasoning that it may be affected by the size distribution of the MSP, as well as by the specific solvents and procedures used in the preparation of monodisperse MSP. We chose PK-84 skin fibroblasts for biocompatibility testing, taking into account the subsequent subcutaneous implantation of PLGA MSP. To obtain a comprehensive appraisal of MSP biocompatibility, we studied the effect of intact MSP and degradation products thereof on PK-84 cells using morphological assessment, mitochondrial activity and cell proliferation as readout parameters.

PK-84 cells formed a monolayer after $72 \mathrm{~h}$. of culture in normal complete medium (Fig. 1a). Direct contact with MSP $(5 \mu \mathrm{m}, 30 \mu \mathrm{m}$ or polydisperse) did not affect monolayer morphology (Fig. 1b-d, respectively). As expected, direct contact with the non-cytotoxic control polymer polyurethane did not affect monolayer integrity (Fig. 1e), while direct contact with the cytotoxic polymer latex resulted in complete disruption of the monolayer and cell death (Fig. 1f). Similar results were obtained after exposing PK-84 cells to medium containing degradation products of PLGA MSP and control polymers (data not shown).

Since incubation of PK-84 cells with PLGA MSP may affect the metabolic activity of the cells in the absence of morphologic alterations, we assessed mitochondrial activity in these cells after incubation with intact PLGA MSP or with leachables extracted therefrom (e.g. solvent residues, low molecular weight oligomers, catalyst residues). Mitochondrial activity in PK-84 cells cultured in control medium was set to $100 \%$ (Fig. $1 \mathrm{~g}$ ). Direct contact with MSP of either size ( $5 \mu \mathrm{m}$ MSP: $120.8 \% \pm 2.9 ; 30 \mu \mathrm{m}$ MSP: $106.6 \% \pm 3.0$; polydisperse MSP $107.0 \% \pm 4.5$ ) or with polyurethane $(91.7 \% \pm 9.7)$ did not decrease mitochondrial activity significantly (Fig. 1g). Upon direct contact with latex, mitochondrial activity decreased to $27.8 \% \pm 8.3(p<0.0001)$ of the control value. Exposure of PK-84 cells to degradation products of MSP did not decrease mitochondrial activity significantly (Fig. 1i), although there was a significant decrease upon exposure to latex leachables $(p<0.0001)$.

Since incubation of PK- 84 cells with PLGA MSP may affect cell proliferation, we measured DNA content as a read-out for potential cell proliferation or death after exposure to MSP. DNA content in normal medium control was set to $100 \%$. Direct contact with MSP of either size (5 $\mu \mathrm{m}$ MSP: $106.7 \% \pm 8.4$; $30 \mu \mathrm{m}$ MSP: $112.9 \% \pm 21.4$; polydisperse MSP: $99.5 \% \pm 3.5$ ), or with polyurethane $(88.8 \% \pm 13.0)$ did not significantly decrease DNA content. Upon direct contact with latex, DNA content decreased significantly $(p<0.0001)$ to $16.7 \% \pm 10.4$ of the control value (Fig. 1h). Exposure of PK-84 cells to leachables of PLGA MSP did not decrease DNA content significantly (Fig. 1j), although there was a significant decrease upon exposure to latex leachables $(p<0.0001)$. In conclusion, PLGA MSP displayed good in vitro biocompatibility, irrespective of size and size distribution. 

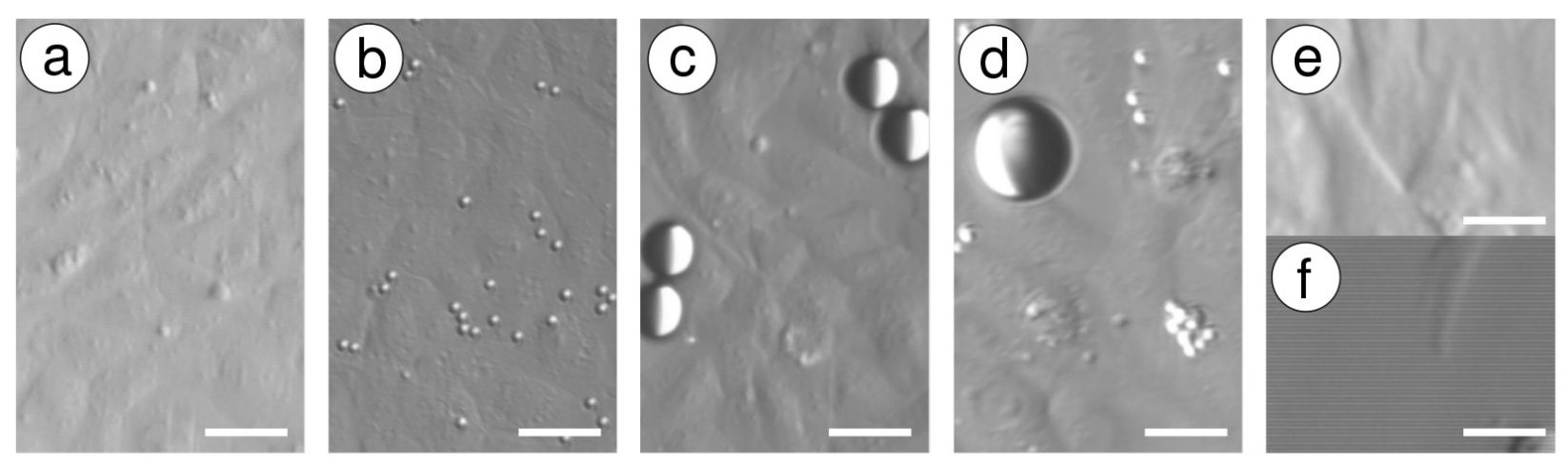

\section{Direct contact}

$\mathrm{g}$
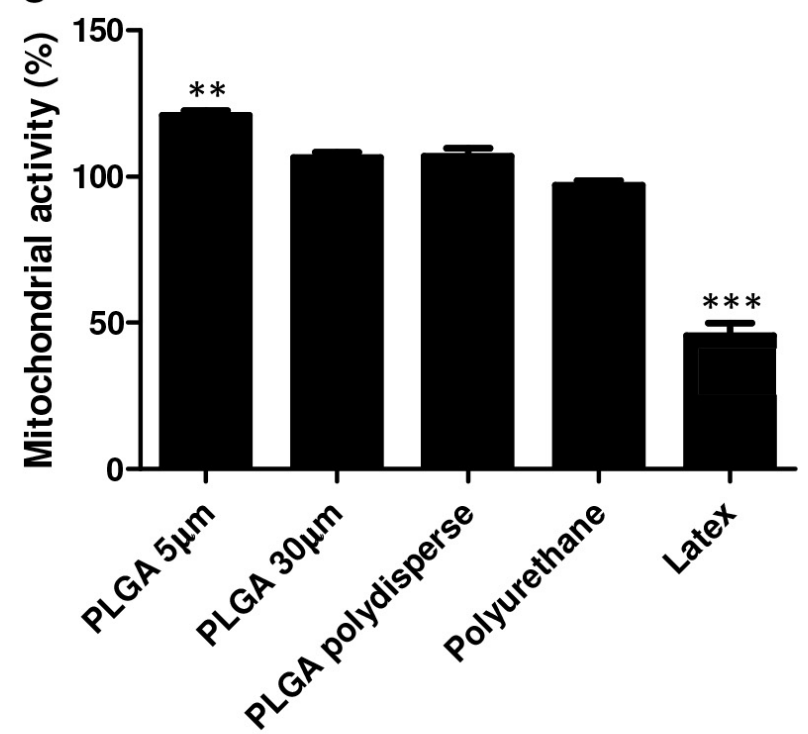

\section{Exposure to leachables}

$$
\text { i }
$$

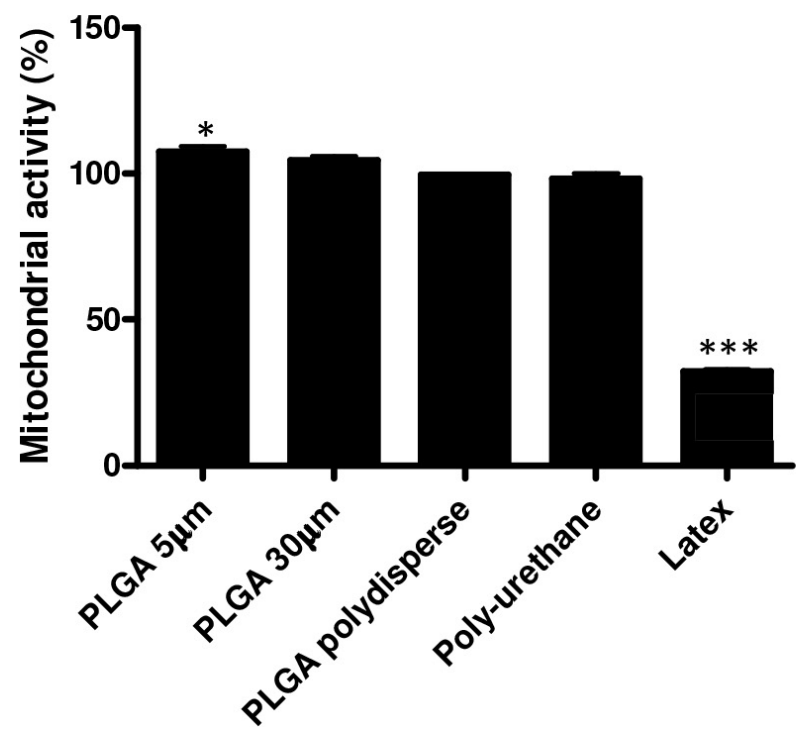

h

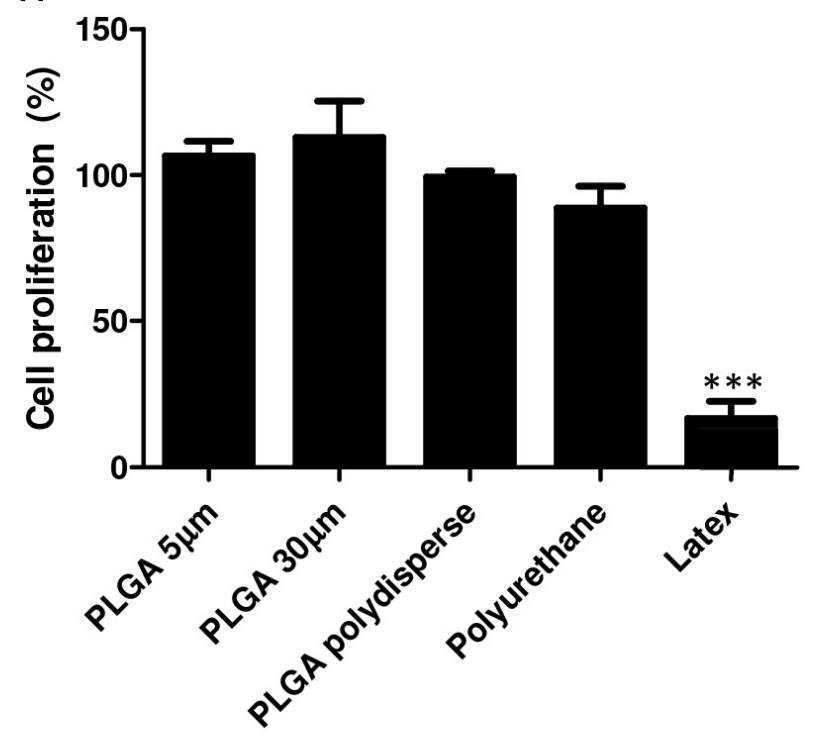

j

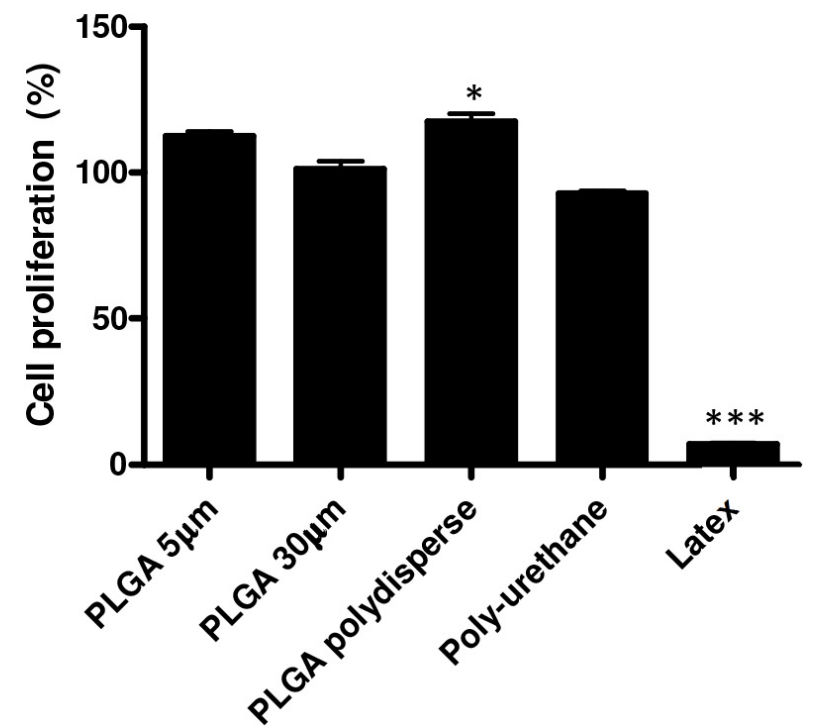

Fig. 1. In vitro biocompatibility of PLGA MSP. PK-84 cells were cultured for $72 \mathrm{~h}$ in medium (a), in direct contact with $5 \mu \mathrm{m}$ PLGA MSP (b), $30 \mu \mathrm{m}$ PLGA MSP (c), polydisperse PLGA MSP (d), polyurethane (e), or latex (f). MSP are visible under the microscope (b-d). Mitochondrial activity was measured using the CellTiter 96 Aqeous One Solution Assay (g, i) and cell proliferation was determined using the CyQuant cell proliferation assay (h, $\mathbf{j})$. Scale bars represent $50 \mu \mathrm{m}$. Bars represent mean values and SEM. ${ }^{*} p<0.05, * * p<0.01$ and $* * * p<0.001$. 
Day 7
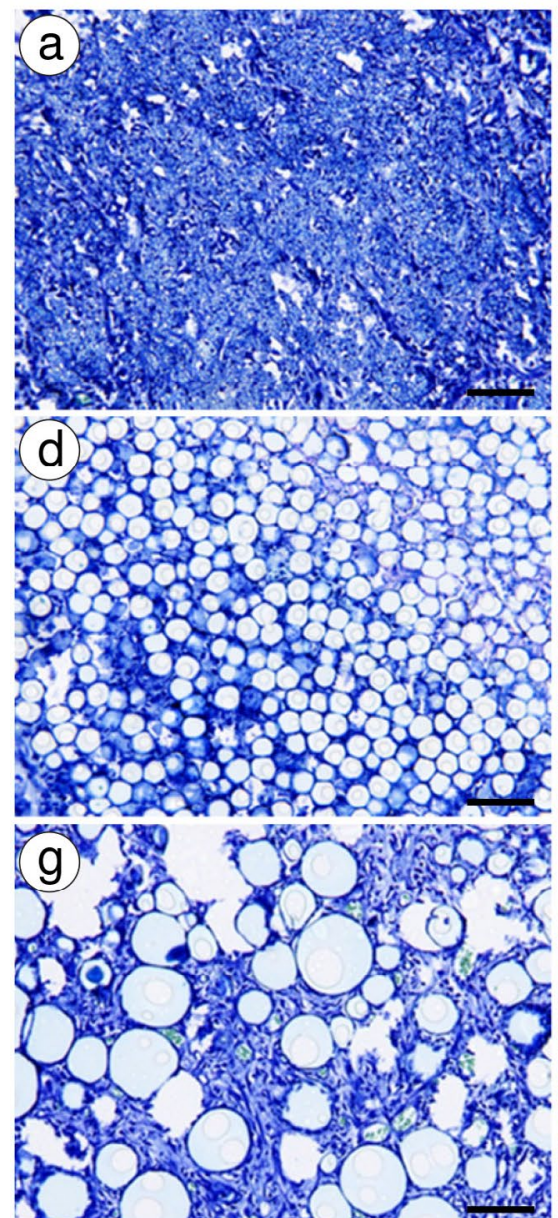

j

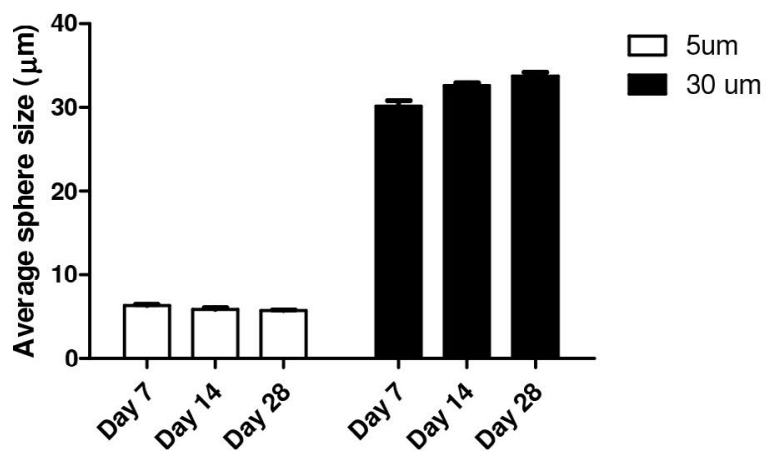

Day 14
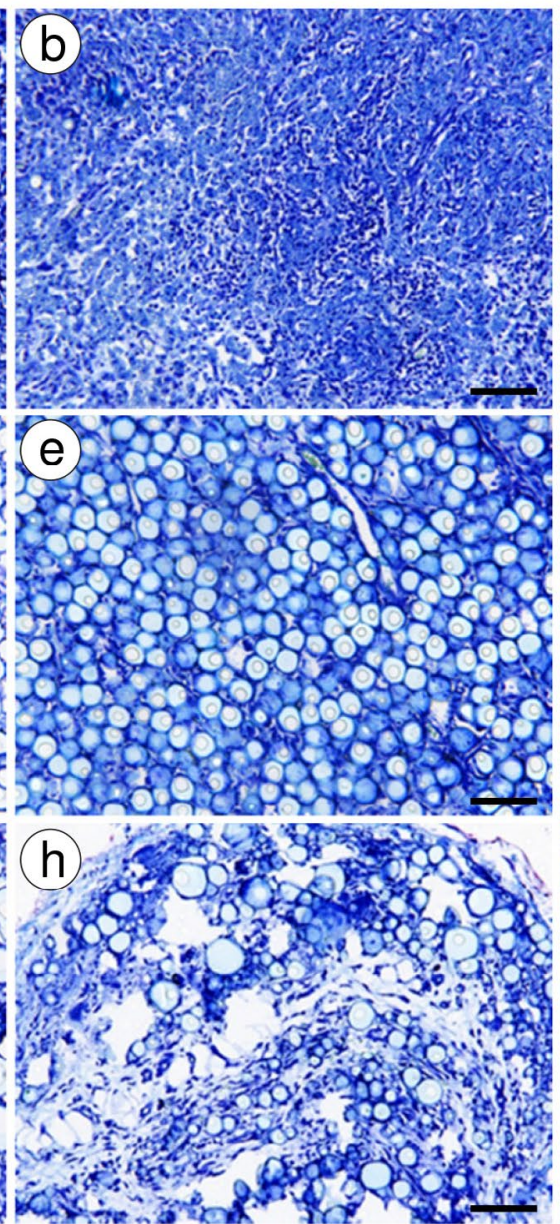

$\mathrm{k}$

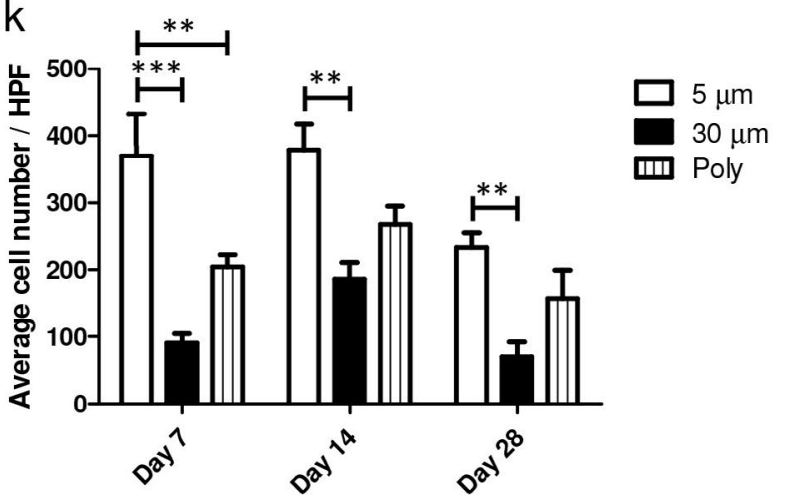

Fig. 2. Cellular influx and MSP degradation. PLGA MSP with a diameter of $5 \mu \mathrm{m}$ (a-c), $30 \mu \mathrm{m}$ (d-f), and polydisperse MSP (g-i) were injected subcutaneously and explanted at day 7, 14 or 28. Average sphere diameter was calculated for each time point $(\mathbf{j})$ where MSP are visible as white spheres, and average cell influx was determined by morphometry (k). Scale bars represent $100 \mu \mathrm{m}$. Bars represent mean values and SEM. ${ }^{* *} p<0.01$ and ${ }^{* * *} p<0.001$. HPF; high power field.

\section{In vivo MSP degradation}

As a prerequisite to understanding the FBR to MSP, we first examined the degradation behaviour of MSP with time, after subcutaneous implantation in rats. Cells were identified by their nuclear morphology after toluidine blue staining, whereas MSP were detectable as unstained, circular structures (Fig. 2a-i). The monodispersity of $5 \mu \mathrm{m}$ and $30 \mu \mathrm{m}$ MSPs was clearly visible. The average diameter of monodisperse MSP did not change significantly with time (Fig. 2j), indicating the absence of degradation by surface erosion. Most probably, the MSP are degraded by bulk type degradation, where the first phase of degradation is characterised by decreasing density of the MSP while dimensions stay more or less the same, and the second phase of degradation is characterised by fragmentation of the MSP into smaller particles until the material has fully degraded. This heterogeneous degradation has been previously described by Engineer et al. (2010). 

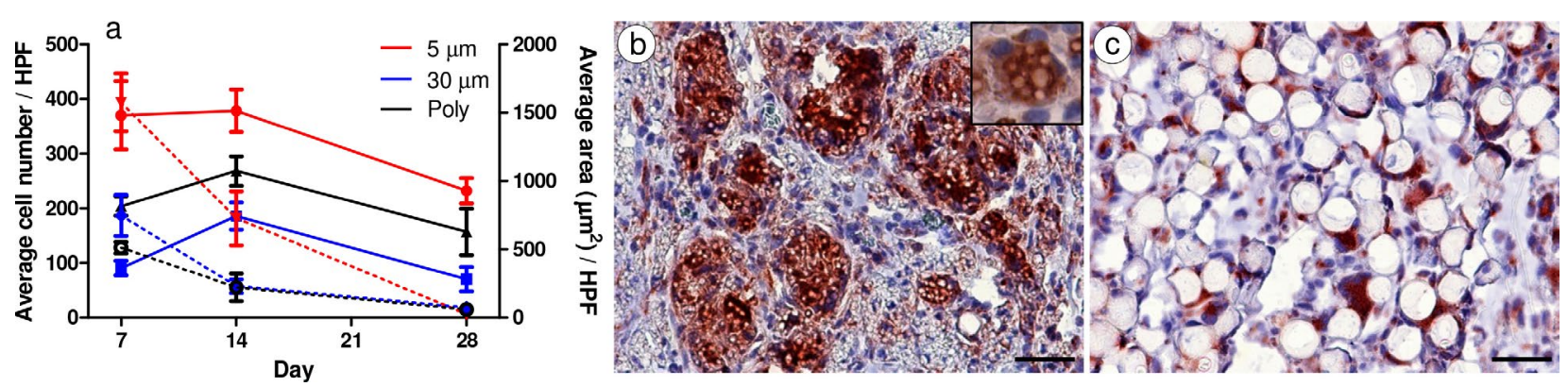

Fig. 3. Macrophage infiltration in relation to total cellularity with time and macrophage behaviour, in relation to MSP size. PLGA MSP with a diameter of $5 \mu \mathrm{m}, 30 \mu \mathrm{m}$ and polydisperse MSP were injected subcutaneously and explanted at day 7, 14 or 28. Average cellular infiltration (solid lines) is shown compared to average ED-1-stained area (dotted lines) (a). PLGA MSP with a diameter of $5 \mu \mathrm{m}(\mathbf{b})$ and $30 \mu \mathrm{m}$ (c) were injected subcutaneously and explanted at day 7. Macrophages phagocytose small $(5 \mu \mathrm{m})$ MSP, as shown by MSP location inside ED-1-stained area (insert), while they attached to large $(30 \mu \mathrm{m})$ MSP. Scale bars represent $50 \mu \mathrm{m}$. Data represent mean values and SEM. HPF; high power field.

Day 7

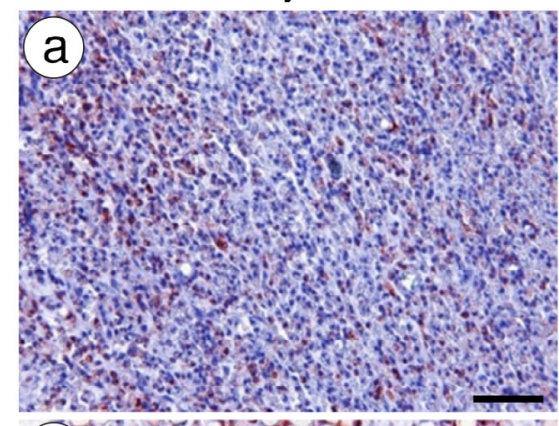

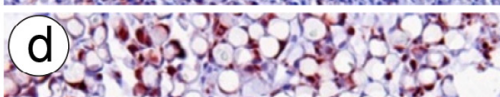

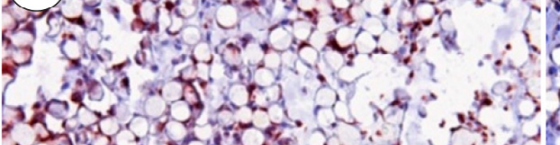
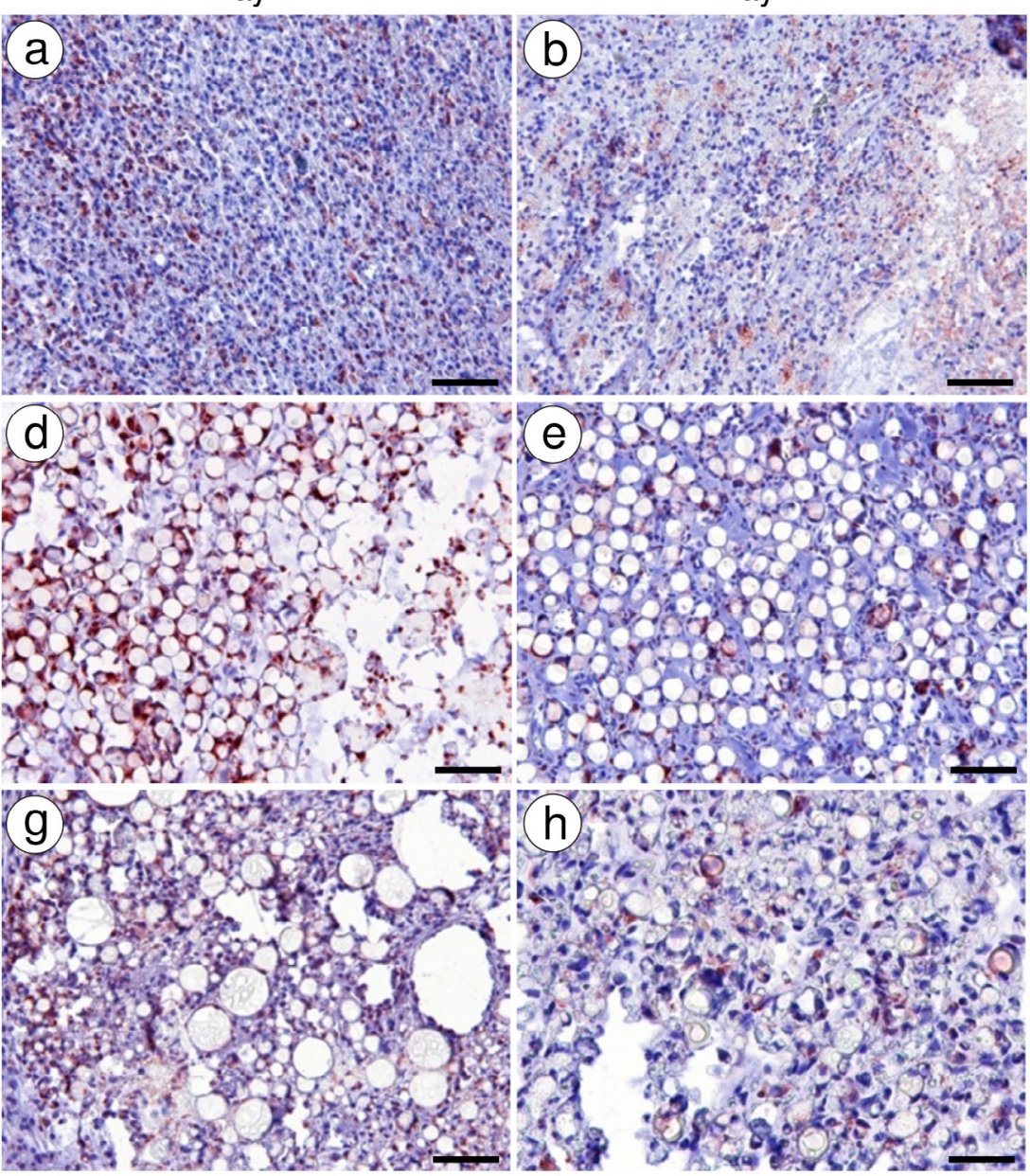

j

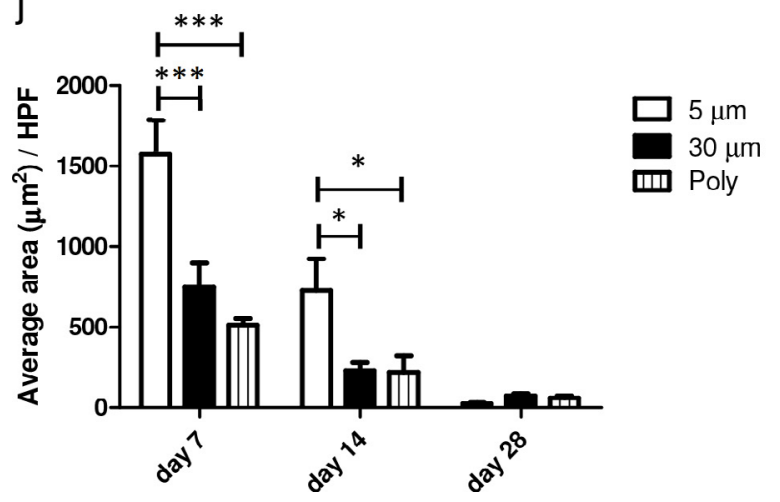

Fig. 4. Macrophage infiltration in $5 \mu \mathrm{m}$ PLGA implants. PLGA MSP of $5 \mu \mathrm{m}$ (a-c), $30 \mu \mathrm{m}$ (d-f), and polydisperse MSP (g-i) were injected subcutaneously and explanted at day 7, 14 or 28 . ED-1 staining was performed to assess macrophage infiltration. Average macrophage area was determined by morphometry (j). Scale bars represent $100 \mu \mathrm{m}$. Bars represent mean values and SEM. $* p<0.05, * * p<0.01$ and $* * * p<0.001$. HPF; high power field. 
Day 7
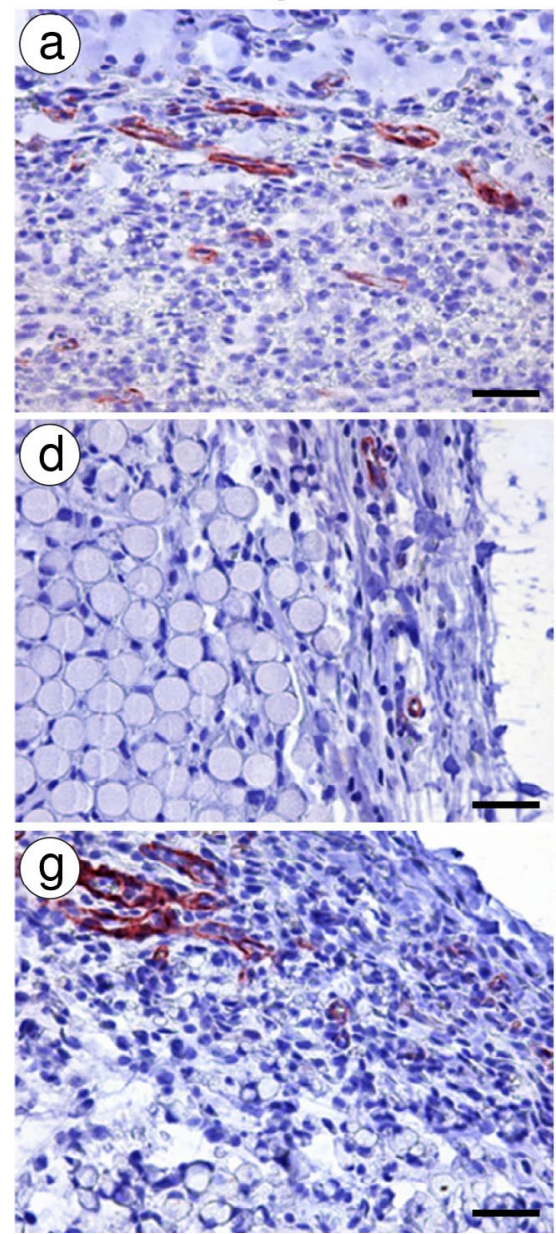

Day 14
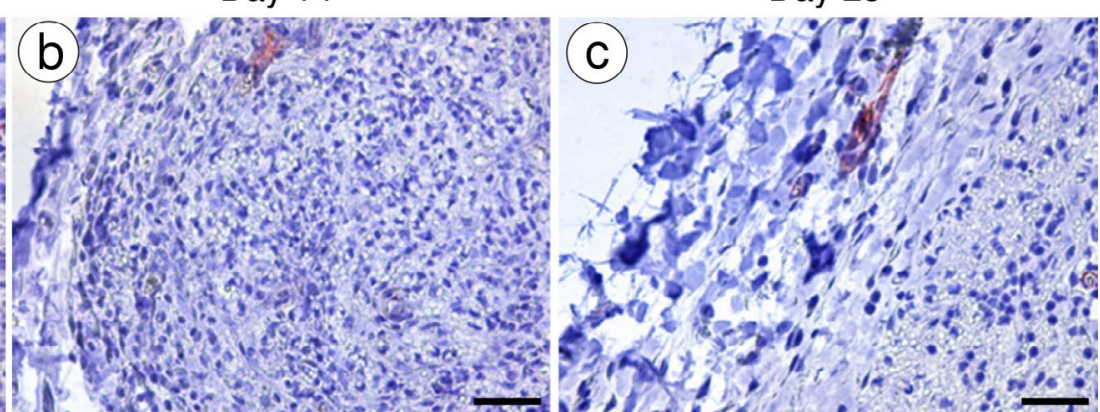
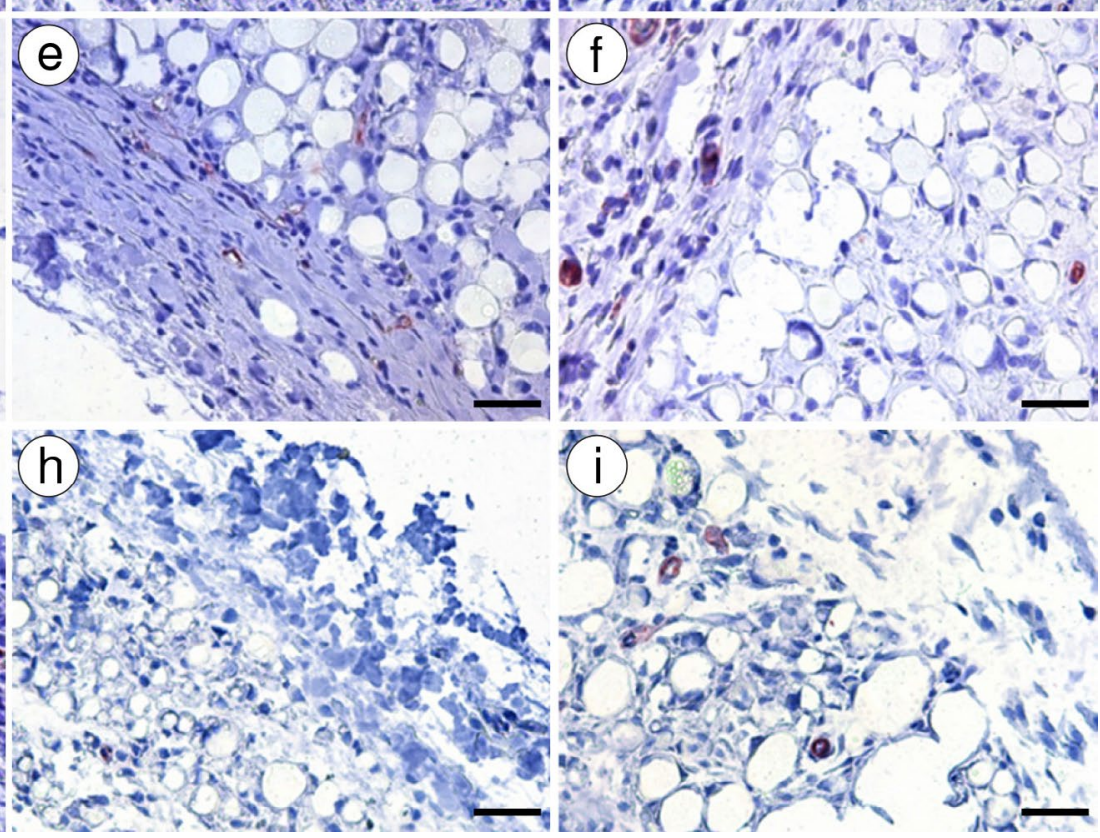

Fig. 5. Assessment of implant encapsulation by myofibroblasts. PLGA MSP with a diameter of $5 \mu \mathrm{m}(\mathbf{a}-\mathbf{c}), 30 \mu \mathrm{m}$ (d-f), and polydisperse MSP (g-i) were injected subcutaneously and explanted at day 7, 14 or 28. Myofibroblasts were detected by smooth muscle actin staining. Scale bars represent $50 \mu \mathrm{m}$.

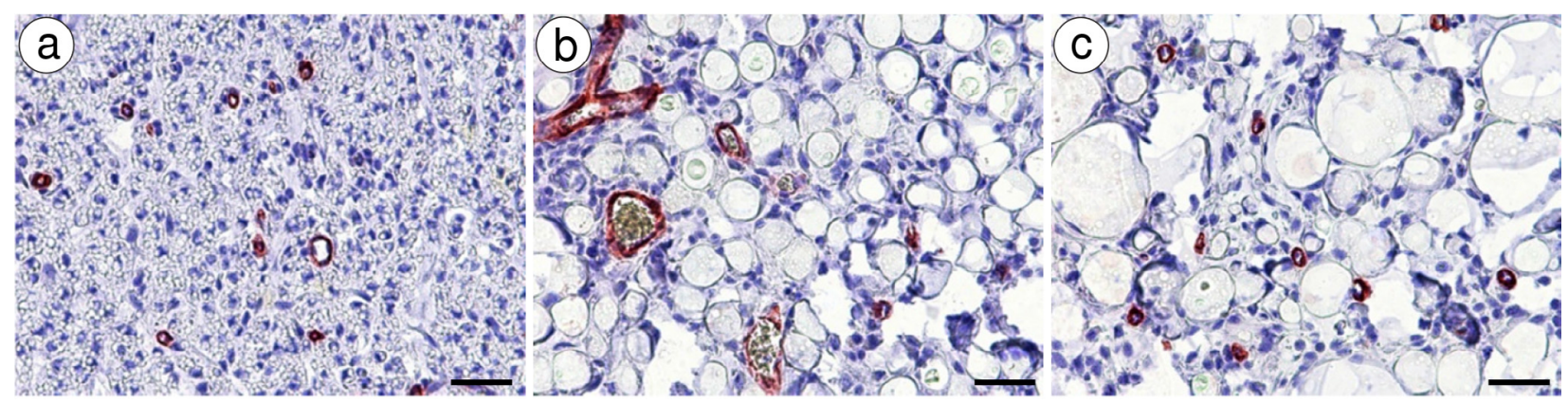

d

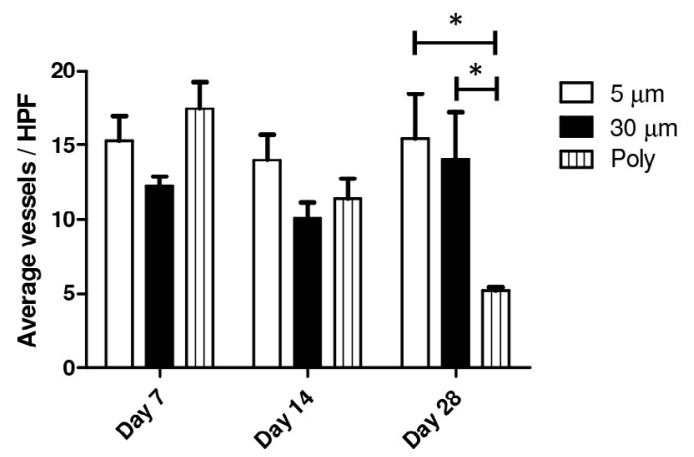

Fig. 6. Vascularisation in PLGA MSP implants. PLGA MSP with a diameter of $5 \mu \mathrm{m}(\mathbf{a}), 30 \mu \mathrm{m}(\mathbf{b})$, and polydisperse MSP (c) were injected subcutaneously and explanted at day 7 . Blood vessels were detected by smooth muscle actin staining of vascular smooth muscle cells. Blood vessels were counted manually (d). Scale bars represent $50 \mu \mathrm{m}$. Bars represent mean values and SEM. HPF; high power field. 
Day 7
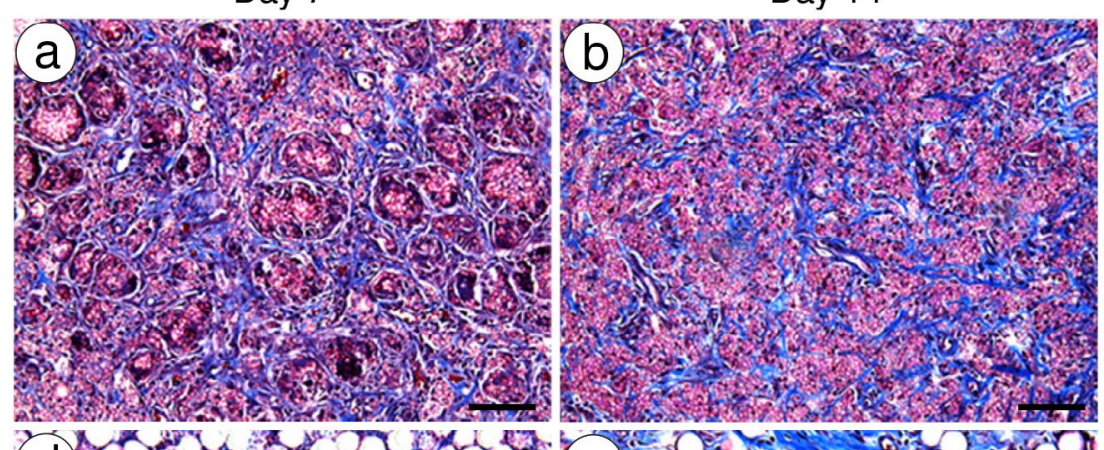

Day 14
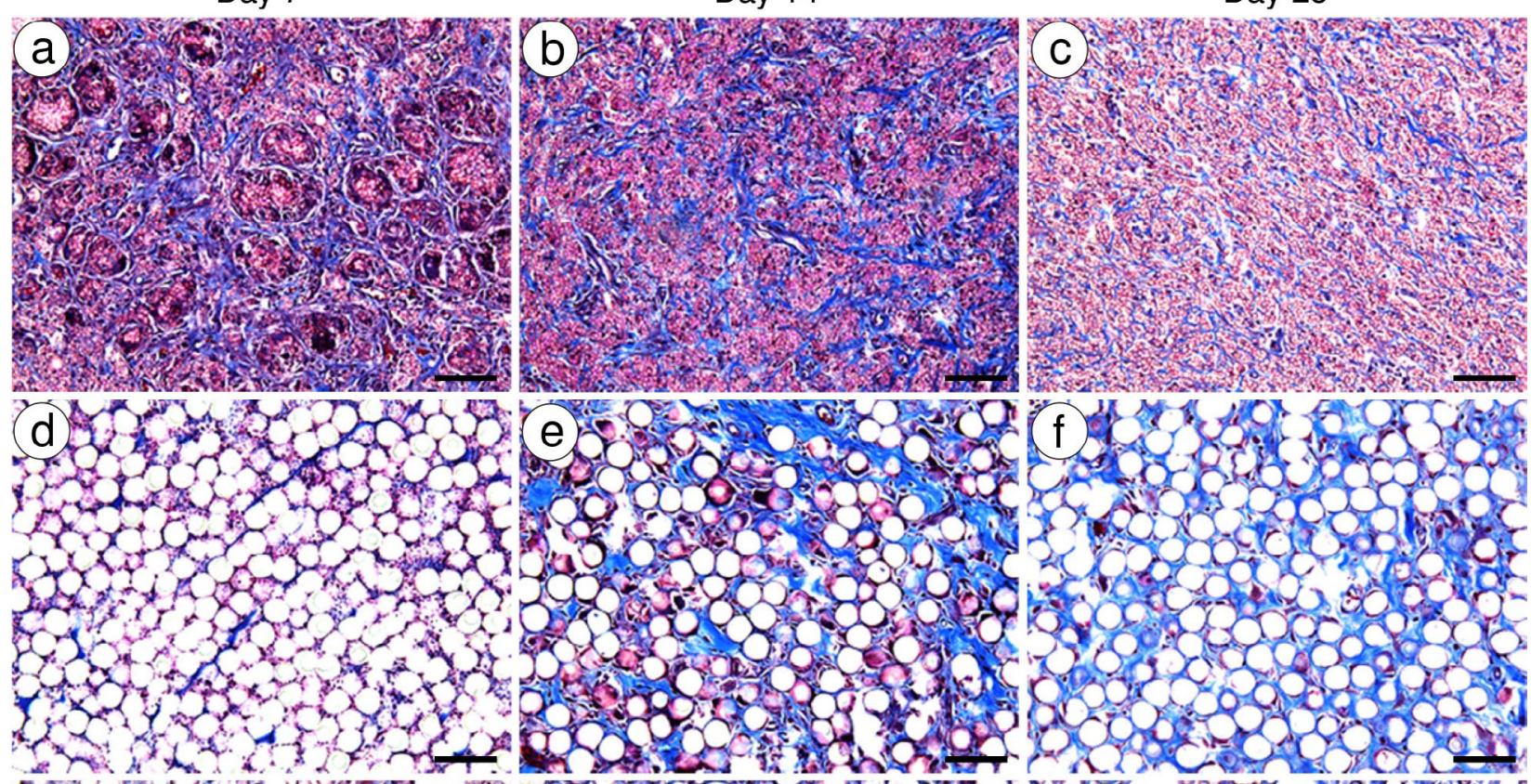
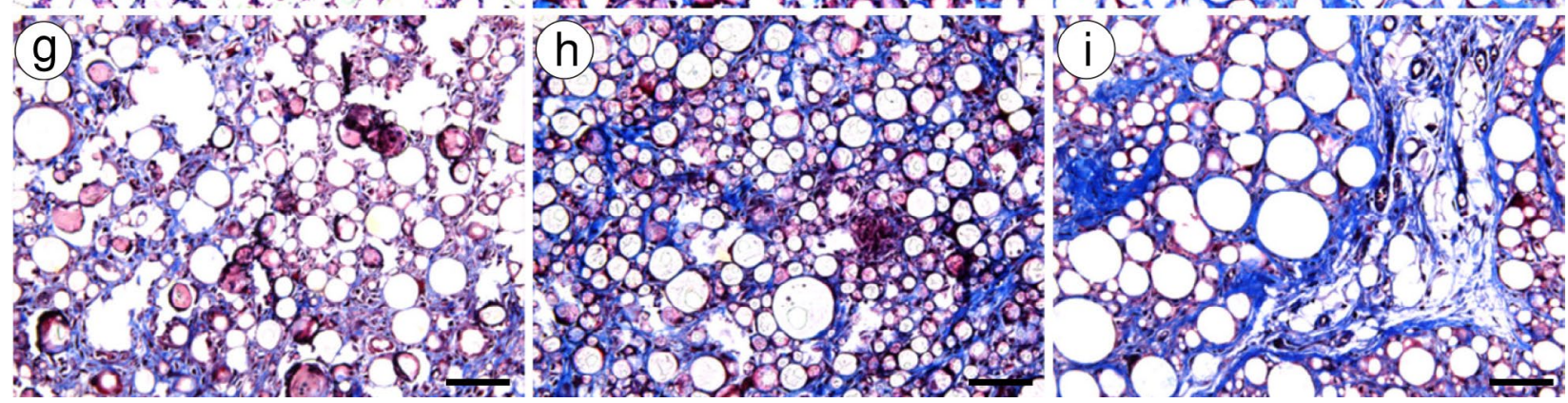

Fig. 7. Extracellular matrix deposition in PLGA MSP implants. PLGA MSP with a diameter of $5 \mu \mathrm{m}(\mathbf{a}-\mathbf{c}), 30 \mu \mathrm{m}$ (d-f), and polydisperse MSP (g-i) were injected subcutaneously and explanted at day 7, 14 and 28. Masson trichrome staining was used to visualise ECM deposition (blue dye). Scale bars represent $100 \mu \mathrm{m}$.

\section{Cellular infiltration in relation to MSP size}

The major hallmark of a FBR is the infiltration of inflammatory cells, in particular macrophages, into the foreign body/implant. To obtain a first, qualitative impression of inflammatory infiltrates in MSP implants, we investigated infiltrating cells morphologically, in relation to MSP size and the duration of the foreign body reaction. Infiltrating cells were present in all MSP implants and at all time-points, irrespective of MSP size, and were mainly located in the spaces between MSP. Judging by nuclear morphology we found that infiltrates consisted virtually entirely of macrophages; no polymorphonuclear cells or lymphocytes were detected. To determine whether MSP size affected the extent of inflammatory cell infiltration, we determined the average cell number per high power field by morphometric quantification. At all time points, implants consisting of $5 \mu \mathrm{m}$ MSP contained significantly larger infiltrates (day 7;5 $5 \mathrm{~m} v s .30 \mu \mathrm{m} p<0.0001$; $5 \mu \mathrm{m} v s$. polydisperse $p=0.0076$; day $14 ; 5 \mu \mathrm{m} v s$. $30 \mu \mathrm{m} p=0.0022$; day $28 ; 5 \mu \mathrm{m} v s .30 \mu \mathrm{m} p=0.0092$ ) than implants consisting of $30 \mu \mathrm{m}$ MSP or polydisperse MSP (with the exception of days 14 and 28) (Fig. 2k). Implants consisting of $30 \mu \mathrm{m}$ MSP were least infiltrated by inflammatory cells at all time-points, albeit not significantly less than implants consisting of polydisperse MSP.

\section{Macrophage recruitment in relation to MSP size}

To confirm the morphological finding that inflammatory infiltrates consisted mainly of macrophages, we performed an ED-1 staining, which identifies macrophages (Fig. 3). Interestingly, despite their clear nuclear morphology indicative of macrophages, not all infiltrating cells expressed ED-1, suggesting that this marker might not detect all macrophages. To gain more insight into the discrepancy between the magnitude of the total cellular infiltrate and the size of ED-1 infiltrates in MSP implants, we measured the ED-1-stained area in implants and plotted it against total cellular infiltrates (Fig. 3a). We found that, while total cellularity remained relatively constant over time, ED-1 infiltrates decreased rapidly. This finding, in combination with the mononuclear morphology of cell infiltrates, suggests that ED-1 expression is downregulated in macrophages with time, rather than that macrophage infiltrates resolve during this observation period.

We further asked whether MSP size affects the behaviour of ED-1 macrophages. Indeed, we found that in 
Day 7

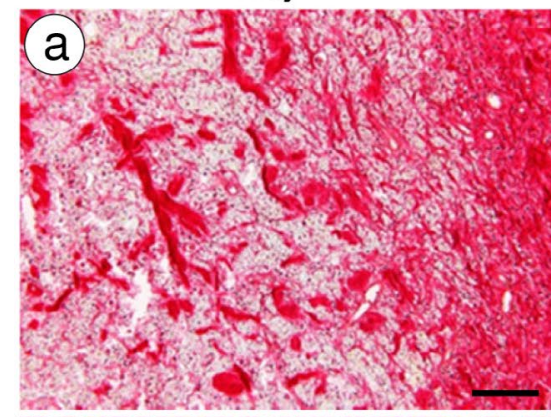

Day 14
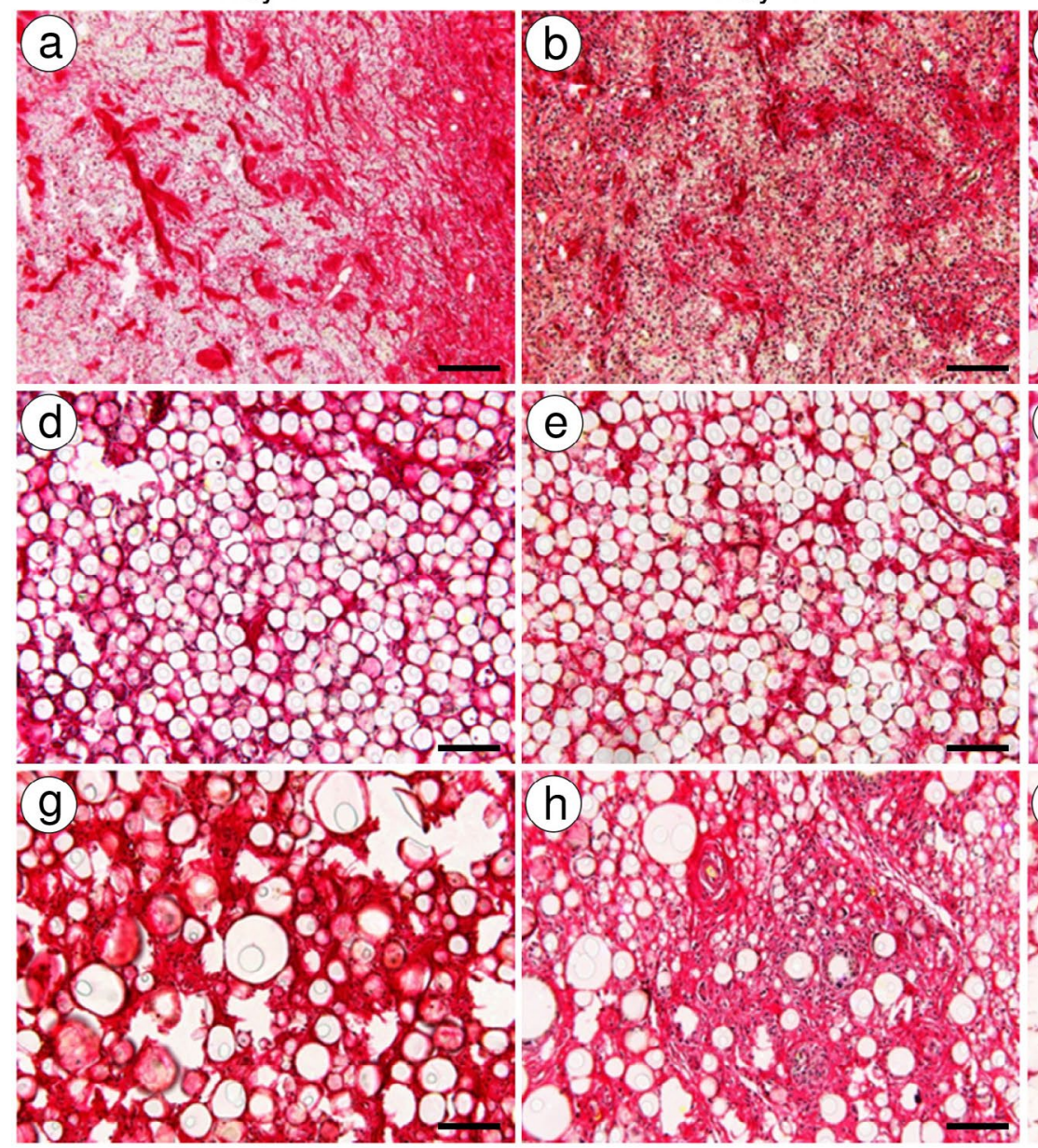

j

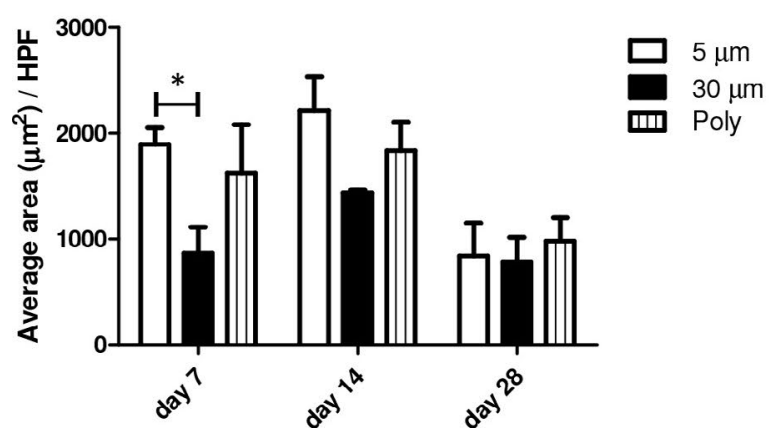

Day 28
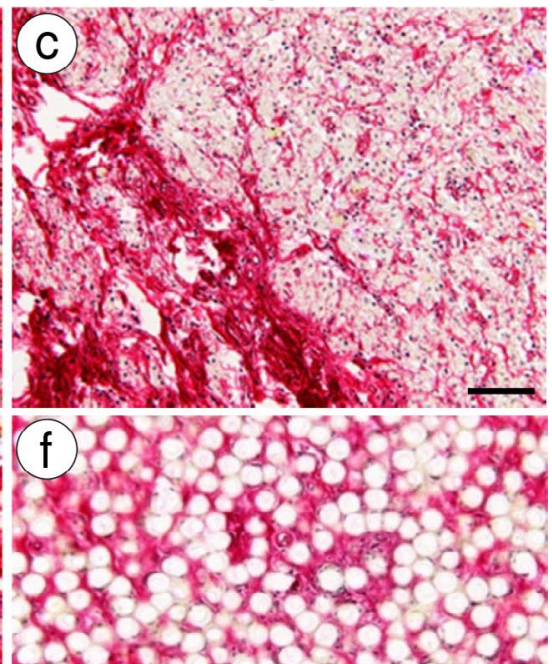
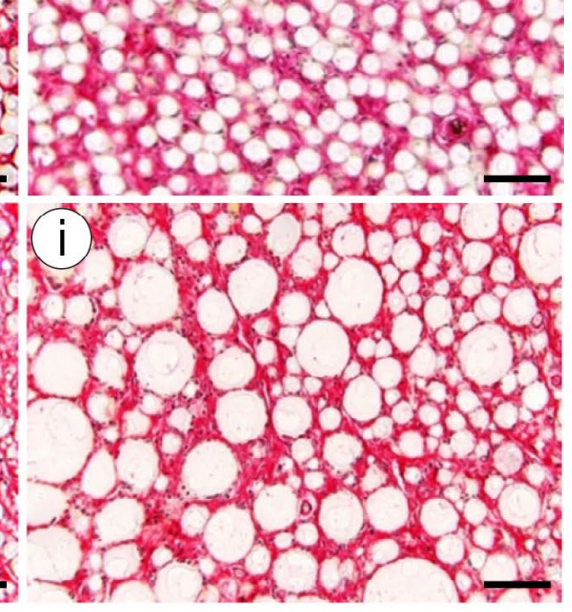

Fig. 8. Detection and quantification of total collagen deposition by Picrosirius red staining. PLGA MSP with a diameter of $5 \mu \mathrm{m}$ (a-c), $30 \mu \mathrm{m}$ (d-f), and polydisperse MSP (g-i) were injected subcutaneously and explanted at day 7, 14 or 28. Total collagen deposition in implants was determined by Picrosirius red staining and quantified by morphometry of stained area $(\mathbf{j})$. Scale bars represent $100 \mu \mathrm{m}$. Bars represent mean values and SEM. HPF; high power field.

implants consisting of $5 \mu \mathrm{m}$ MSP, some ED-1 macrophages were interspersed between MSP, while many clustered and appeared to contain phagocytosed MSP (Fig. 3b). In contrast, in implants consisting of $30 \mu \mathrm{m}$ MSP, ED-1 macrophages were located in the interstitial spaces between MSP and on MSP, and no phagocytosis was visible. ED-1 macrophages formed a one-cell-layer around MSP, or, occasionally, were fused to giant cells (Fig. 3c).

Finally, we assessed whether MSP size influenced the extent of ED-1 macrophage infiltration into implants (Fig. 4). Quantification (Fig. 4j) of ED-1-positive infiltrates (Fig. 4a-i) revealed that implants consisting of $5 \mu \mathrm{m}$ MSP contained significantly more ED-1 macrophages on day 7 and 14 than implants consisting of $30 \mu \mathrm{m}$ or polydisperse MSP (day 7; $5 \mu \mathrm{m} v s .30 \mu \mathrm{m} p=0.0030$,
$5 \mu \mathrm{m} v s$. polydisperse $p<0.0001$; day $14 ; 5 \mu \mathrm{m} v s .30 \mu \mathrm{m}$ $p=0.0220,5 \mu \mathrm{m} v s$. polydisperse $p=0.0193$ ). There were no significant differences in macrophage infiltration between implants consisting of $30 \mu \mathrm{m}$ or polydisperse MSP.

\section{Implant encapsulation and vascularisation}

Solid foreign body implants are generally encapsulated by (myo)fibroblasts, in an attempt to isolate the foreign material from body tissue. To determine whether MSP implants were encapsulated, we performed an $\alpha \mathrm{SMA}$ staining to visualise myofibroblasts (Fig. 5). Although sporadic myofibroblasts were detected at the periphery of implants, no fibrous capsules were detected around any of the implants at any time point. Myofibroblasts were 
also not present inside implants. $\alpha$ SMA also identifies vascular smooth muscle cells, which allowed us to detect and quantify blood vessels in relation to MSP size (Fig. 6 ). We found no significant differences in vascularisation between implants of various MSP sizes on day 7 and 14 . However, at day 28, vascularisation was significantly lower in implants consisting of polydisperse MSP than in implants consisting of monodisperse MSP (5 $\mu \mathrm{m}$ and $30 \mu \mathrm{m} p=0.0032$ and 0.0100 , respectively).

\section{ECM deposition in relation to MSP size}

To investigate possible ECM deposition in implants in relation to MSP size, we performed a Masson trichrome staining (Fig. 7), in which the aniline blue component stains ECM. On day 7, ECM deposition was more pronounced in implants consisting of $5 \mu \mathrm{m}$ MSP than in implants consisting of polydisperse or $30 \mu \mathrm{m}$ MSP. These differences were less pronounced at later time points. Irrespective of MSP size, ECM deposition was highest on day 14 and diminished on day 28. Since the Aniline blue component of the Masson trichrome staining could not be accurately quantified, we additionally performed a Picrosirius red staining (Fig. 8), which allows detection and quantification of collagens. Quantification of the Picrosirius red staining confirmed that collagen deposition was significantly higher $(p=0.0487)$ in $5 \mu \mathrm{m}$ MSP implants than in $30 \mu \mathrm{m}$ MSP implants (Fig. 8j). This difference was also present on day 14, albeit not significantly. Moreover, we confirmed that collagen amount was lowest on day 28 for all implants.

\section{Discussion}

In this study we investigated the effect of MSP size on the FBR towards PLGA microspheres and found that large $(30 \mu \mathrm{m})$ MSP elicit a mild FBR without phagocytosis of MSP, in contrast to small (5 $\mu \mathrm{m}) \mathrm{MSP}$, which are phagocytosed during the course of a strong FBR.

The first clear evidence that particle size determines the extent of the FBR to PLGA MSP was provided by the significantly lower cellular infiltration in implants consisting of $30 \mu \mathrm{m}$ MSP compared to $5 \mu \mathrm{m}$ MSP implants. A reason for this difference might be increased steric hindrance in $30 \mu \mathrm{m}$ MSP, meaning that cells have more difficulty infiltrating between these large MSP. Moreover, the tissue response to MSP may vary in relation to particle size and may affect the ensuing inflammatory response via mechanisms that need to be determined.

To further study the composition of cellular infiltrates in MSP implants, we focused on macrophages, which can degrade PLGA scaffolds (Thevenot et al., 2010). We confirmed that significantly more macrophages infiltrated $5 \mu \mathrm{m}$ MSP implants than $30 \mu \mathrm{m}$ MSP implants, again supporting a role for particle size in determining the extent of the FBR. Importantly, a role for shape and chemistry can be excluded in this study. Degradation products may have influenced the FBR, but as all MSP were made from the same material, this still allows comparison of the FBR based on size. The finding of increased macrophage influx in $5 \mu \mathrm{m}$ MSP implants may be explained by the study of Damoiseaux et al. (1994), who have shown that macrophages increase their ED-1 expression under phagocytotic stimulation. Indeed, alongside the increased macrophage infiltration in $5 \mu \mathrm{m}$ MSP implants, we also found phagocytosis of these small particles, whereas phagocytosis of large particles was absent. Moreover, if the phagocytic stimulus is responsible for ED-1 expression on macrophages, the declining number of ED-1 macrophages in $5 \mu \mathrm{m}$ MSP implants over time may be explained by the virtually complete phagocytosis of $5 \mu \mathrm{m}$ MSP by day 28 . However, this explanation does not hold for the drop in ED-1 macrophage numbers in $30 \mu \mathrm{m}$ and polydisperse MSP implants and suggests that additional, yet unknown mechanisms may play a further role in macrophage function.

Next to inflammatory cell infiltration, encapsulation of foreign bodies, such as biomaterials, is a hallmark of the FBR. The thickness of the foreign body capsule has been used as a measure for the severity of the FBR (Vacanti et al., 2012). The sporadic presence of myofibroblasts in our model suggests that small, distinct and separate microparticles do not trigger the encapsulation process, while large, compact implants do.

Vascularisation of implants is relevant for implant integration and degradation, depending on the desired function of the implant. We found no significant differences in vascularisation between $5 \mu \mathrm{m}$ and $30 \mu \mathrm{m}$ MSP implants. There was a significant decrease in vascularisation in polydisperse MSP implants on day 28, for which we do not have an explanation so far. Degradation products of PLGA are known to indirectly induce vascularisation (Porporato et al., 2012). However, the first phase of degradation of the PLGA MSP is the same for all MSP sizes. We expect that the second phase of PLGA degradation has not yet started based on the unchanged MSP size in our timeframe, and it may well be that differences in vascularisation may occur at later time points, once fragmentation into smaller particles sets in.

Finally, we studied the effect of MSP size on ECM deposition within implants, since the presence of collagens may influence drug penetration from the MSP towards the surrounding tissue. The higher collagen deposition in $5 \mu \mathrm{m}$ MSP implants compared to $30 \mu \mathrm{m}$ and polydisperse MSP implants was surprising, since myofibroblasts, the main producers of collagen, were sporadic in all implants. Possibly, other cells may be responsible for the production of collagens, among which ED-1-positive macrophages are the prime candidates, since they virtually exclusively formed the foreign body infiltrates.

Only a few studies have addressed the effect of (bio) material size and the host response. However, the study of Dreifke et al. (2013) mainly focused on drug release, mechanical support and adherence of cells, but did not investigate the magnitude of inflammation in relation to size. Some circumstantial evidence can be derived from the study of Litvack et al. (2011), who showed that macrophages can phagocytose red blood cells with a diameter of $7-10 \mu \mathrm{m}$. While this study describes the phagocytosis of natural, body-derived particles, a process in which additional factors, such as immunoglobulin coating, might play a role, it allows the postulate that 
the size of artificial particles, such as MSP, may affect phagocytotic behaviour of macrophages. We have addressed this possibility, extending the particle size beyond $8 \mu \mathrm{m}$, the maximal particle size studied by Litvak et al. (2011), and show that this is indeed the case.

We have chosen PLGA as a model polymer since it is used in various microsphere-based drug delivery products that have been cleared by the FDA. PLGA can degrade within weeks or months, depending on the monomer ratio (Li et al., 2011). In our study, we have chosen a PLGA type that allows in vivo investigation over a longer time period. Our in vivo findings confirmed that the PLGA MSP were hardly degraded over a period of four weeks. Note that in the course of degradation of the PLGA MSP degradation products are formed, initially primarily low molecular weight DL-lactide-co-glycolide oligomers. These degradation products may have influenced the FBR. However, all MSP were made from the same material, therefore, the current study still allows comparison of the FBR based on MSP size.

We used monodisperse MSP, therefore our findings can link the extent of the FBR to a distinct size and shape of the drug delivery vehicle. They show that MSP size clearly determines aspects of the FBR, such as cellular, and specifically macrophage, infiltration into the implant, macrophage function and ECM deposition. For future therapeutic applications, our findings imply that 1) monodisperse MSP are superior to polydisperse MSP due to their better injectability and controllable drug release profile; 2) since larger size MSP are not phagocytosed, they are adequate for interstitial drug delivery, where the drug is required to bind to receptors on the cell surface; 3) since small MSP are phagocytosed, they may be adequate for intracellular drug delivery; 4) MSP, irrespective of size, have the advantage of not being encapsulated, implying that penetration of the drug to surrounding tissue is not hampered by a fibrous capsule. Obviously, next to these implications of our findings for possible therapeutic applications of MSP, the mechanisms that underlie the differential FBR to distinct MSP sizes deserve further investigation.

\section{Conclusions}

MSP size affects the extent of the FBR, as reflected by differences in cellular, and specifically macrophage, influx into MSP implants, phagocytic behaviour of macrophages and the deposition of ECM in the implants. Therefore, MSP size is predicted to have an important influence on therapeutic outcome of drug-loaded MSP. Taken together, we propose that $30 \mu \mathrm{m}$ MSP should preferably be used for interstitial drug delivery compared to $5 \mu \mathrm{m}$ and polydisperse MSP, while $5 \mu \mathrm{m}$ MSP could be an interesting candidate for intracellular drug delivery.

\section{Acknowledgements}

We thank Nicole Irving for her technical assistance. This research forms part of the Project P3.02 DESIRE of the research program of the BioMedical Materials Institute, co-funded by the Dutch Ministry of Economic Affairs. The financial contribution of the Dutch Kidney Foundation is gratefully acknowledged. We wish to confirm that there are no known conflicts of interest associated with this publication and there has been no significant financial support for this work that could have influenced its outcome.

\section{References}

Anderson JM (2001) Biological responses to materials. Annu Rev Mater Res 31: 81-110.

Bhardwaj U, Sura R, Papadimitrakopoulos F, Burgess DJ (2010) PLGA/PVA hydrogel composites for long-term inflammation control following s.c. implantation. Int $\mathrm{J}$ Pharm 384: 78-86.

Cadee JA, Brouwer LA, den OW, Hennink WE, van Luyn MJ (2001) A comparative biocompatibility study of microspheres based on crosslinked dextran or poly(lacticco-glycolic)acid after subcutaneous injection in rats. $\mathrm{J}$ Biomed Mater Res 56: 600-609.

Champion JA, Mitragotri S (2006) Role of target geometry in phagocytosis. Proc Natl Acad Sci USA 103: 4930-4934.

Champion JA, Walker A, Mitragotri S (2008) Role of particle size in phagocytosis of polymeric microspheres. Pharm Res 25: 1815-1821.

Damoiseaux JG, Dopp EA, Calame W, Chao D, MacPherson GG, Dijkstra CD (1994) Rat macrophage lysosomal membrane antigen recognized by monoclonal antibody ED1. Immunology 83: 140-147.

De Groot CJ, van Luyn MJ, Van Dijk-Wolthuis WN, Cadee JA, Plantinga JA, den Otter W, Hennink WE (2001) In vitro biocompatibility of biodegradable dextran-based hydrogels tested with human fibroblasts. Biomaterials 22: 1197-1203.

Dreifke MB, Ebraheim NA, Jayasuriya AC (2013) Investigation of potential injectable polymeric biomaterials for bone regeneration. J Biomed Mater Res A 101: 24362447.

Engineer C, Parikh J, Raval A (2010) Hydrolytic degradation behavior of 50/50 poly lactide-co-glycolide from drug eluting stents. Trends Biomater Artif Organs 24: 131-138.

Enriquez GG, Rizvi SA, D’Souza MJ, Do DP (2013) Formulation and evaluation of drug-loaded targeted magnetic microspheres for cancer therapy. Int J Nanomed 8: 1393-1402.

Felix Lanao RP, Bosco R, Leeuwenburgh SC, KerstenNiessen MJ, Wolke JG, van den Beucken JJ, Jansen JA (2013) RANKL delivery from calcium phosphate containing PLGA microspheres. J Biomed Mater Res A 101: 3123-3130.

Gelb H, Schumacher HR, Cuckler J, Ducheyne P, Baker DG (1994) In vivo inflammatory response to polymethylmethacrylate particulate debris: effect of size, morphology, and surface area. J Orthop Res 12: 83-92.

Hoekstra JW, Ma J, Plachokova AS, Bronkhorst EM, Bohner M, Pan J, Meijer GJ, Jansen JA, van den Beucken JJ 
(2013) The in vivo performance of CaP/PLGA composites with varied PLGA microsphere sizes and inorganic compositions. Acta Biomater 9: 7518-7526.

Jones AJ, Putney S, Johnson OL, Cleland JL (1997) Recombinant human growth hormone poly(lactic-coglycolic acid) microsphere formulation development. Adv Drug Deliv Rev 28: 71-84.

Kusaka T, Nakayama M, Nakamura K, Ishimiya M, Furusawa E, Ogasawara K (2014) Effect of silica particle size on macrophage inflammatory responses. PLoS One 9: e92634.

Lanao RP, Jonker AM, Wolke JG, Jansen JA, van Hest JC, Leeuwenburgh SC (2013) Physicochemical properties and applications of poly(lactic-co-glycolic acid) for use in bone regeneration. Tissue Eng Part B Rev 19: 380-390.

Li J, Stayshich RM, Meyer TY (2011) Exploiting sequence to control the hydrolysis behavior of biodegradable PLGA copolymers. J Am Chem Soc 133: 6910-6913.

Litvack ML, Post M, Palaniyar N (2011) IgM promotes the clearance of small particles and apoptotic microparticles by macrophages. PLoS One 6: e17223.

Lu JM, Wang X, Marin-Muller C, Wang H, Lin PH, Yao Q, Chen C (2009) Current advances in research and clinical applications of PLGA-based nanotechnology. Expert Rev Mol Diagn 9: 325-341.

Makadia HK, Siegel SJ (2011) Poly lactic-co-glycolic acid (PLGA) as biodegradable controlled drug delivery carrier. Polymers 3: 1377-1397.

Okada H (1997) One- and three-month release injectable microspheres of the LH-RH superagonist leuprorelin acetate. Adv Drug Deliv Rev 28: 43-70.

Onuki Y, Bhardwaj U, Papadimitrakopoulos F, Burgess DJ (2008) A review of the biocompatibility of implantable devices: current challenges to overcome foreign body response. J Diabetes Sci Technol 2: 1003-1015.

Paul D, Achouri S, Yoon YZ, Herre J, Bryant CE, Cicuta P (2013) Phagocytosis dynamics depends on target shape. Biophys J 105: 1143-1150.

Petrie Aronin CE, Sadik KW, Lay AL, Rion DB, Tholpady SS, Ogle RC, Botchwey EA (2009) Comparative effects of scaffold pore size, pore volume, and total void volume on cranial bone healing patterns using microspherebased scaffolds. J Biomed Mater Res A 89: 632-641.

Porporato PE, Payen VL, De Saedeleer CJ, Preat V, Thissen JP, Feron O, Sonveaux P (2012) Lactate stimulates angiogenesis and accelerates the healing of superficial and ischemic wounds in mice. Angiogenesis 15: 581-592.

Shive MS, Anderson JM (1997) Biodegradation and biocompatibility of PLA and PLGA microspheres. Adv Drug Deliv Rev 28: 5-24.

Thevenot PT, Nair AM, Shen J, Lotfi P, Ko CY, Tang L (2010) The effect of incorporation of SDF-1alpha into PLGA scaffolds on stem cell recruitment and the inflammatory response. Biomaterials 31: 3997-4008.

Vacanti NM, Cheng H, Hill PS, Guerreiro JD, Dang TT, Ma M, Watson S, Hwang NS, Langer R, Anderson DG (2012) Localized delivery of dexamethasone from electrospun fibers reduces the foreign body response. Biomacromolecules 13: 3031-3038.

Veldhuis G, Gironés M, Bingham D (2009) Monodisperse microspheres for parenteral drug delivery. Drug Deliv Technol 9: 24-31.

\section{Discussion with Reviewers}

Reviewer II: If steric hindrance impacts the ability for cells to infiltrate between $30 \mu \mathrm{m}$ microspheres, should this have been controlled for in this study?

Authors: This is an interesting concept raised by the reviewer; however, we feel this would be difficult to control for in this study, and no method immediately springs to mind. Furthermore, if steric hindrance would indeed impact the ability of cells to infiltrate between $30 \mu \mathrm{m}$ microspheres, compared to smaller sizes, then this would indeed be a (partial) explanation for the differences in the FBR as shown in this study. Therefore, we would argue it is a factor to be recognised, but not primarily controlled for.

Reviewer II: Will the cells recognize two $30 \mu \mathrm{m}$ MSPs that have agglomerated in the tissues as one bigger particle?

Authors: Based on our current results, also taking into account the FBR as seen against the polydisperse MSP, we do not expect this to be the case. We hypothesise that a cell can "measure" a foreign body object up to a certain size which it can phagocytose. All other MSP, at least in our experiments, elicit the same reaction, as being too large for phagocytosis.

Reviewer II: What happens if the MSP are implanted for over $28 \mathrm{~d}$ ? Will the results (such as foreign body formation) be altered with the attachment of drugs to the MSP?

Authors: We did not perform experiments with these MSP for longer time-points. However, it is to be expected that there will be a secondary FBR at the time when these MSP degrade, caused by the small particles and the acids that originate from the degrading MSP. In a pilot study using another type of MSP we incorporated an anti-inflammatory drug and we observed a decreased inflammatory response combined with less collagen deposition (decreased FBR). Therefore, we hypothesise that the FBR can be altered by releasing drugs from MSP. However, this depends on the type of drug, amount of drug released, and the activity of the drug. 